Federal Reserve Bank of Minneapolis

Research Department Staff Report 213

July 1996

\title{
Class Systems and the Enforcement of Social Norms*
}

\author{
Harold L. Cole
}

Federal Reserve Bank of Minneapolis

George L. Mailath

University of Pennsylvania

\section{Andrew Postlewaite}

University of Pennsylvania

\begin{abstract}
We analyze a model in which there is socially inefficient competition among people. In this model, self-enforcing social norms can potentially control the inefficient competition. However, the inefficient behavior often cannot be suppressed in equilibrium among those with the lowest income due to the ineffectiveness of sanctions against those in the society with the least to lose. We demonstrate that in such cases, it may be possible for society to be divided into distinct classes, with inefficient behavior suppressed in the upper classes but not in the lower.
\end{abstract}

\footnotetext{
"Original title: "Enforceability of Social Norms." This paper has benefited from the comments of the participants of a number of seminars. Mailath and Postlewaite gratefully acknowledge support from the National Science Foundation. Mailath thanks the Australian National University for its gracious hospitality while this version was written. The views expressed herein are those of the authors and not necessarily those of the Federal Reserve Bank of Minneapolis or the Federal Reserve System.
} 
"Freedom's just another word for nothin' left to lose"

ME AND BOBBY McGEE (Kris Kristofferson)

\section{Introduction}

Conflicts of interest are a ubiquitous aspect of human interactions. A wide variety of social institutions has evolved to channel and contain these conflicts. Moreover, this variety potentially explains differences among the economic, as well as the social, behavior in different societies. It is well understood that repeated interactions can enhance efficiency by allowing equilibrium behavior that cannot be optimal in one-off transactions. By and large, the discussions of the efficiency improvements that are made possible by repeated interactions abstract from heterogeneities among agents. In this paper, we focus on heterogenous societies and explain how class systems can naturally ameliorate economic conflicts in them.

We are interested in social norms of behavior that control, to some extent at least, economic conflicts. The conflicts we focus on are those in which agents behave self-interestedly, ignoring the consequences of their behavior on others. Any social norm that ameliorates such self-interested behavior requires, implicitly or explicitly, sanctions to be imposed on individuals deviating from the social norm. However, some individuals may find the benefit in deviating from the prescribed behavior greater than the cost of the sanctions resulting from a deviation. While raising the costs is one obvious solution, there are limits. Even death may not be enough to deter a starving person from stealing bread. Although not necessary, it will help to focus our discussion to restrict attention to voluntary associations in which ostracism is the most severe punishment.

A social norm of behavior, then, is limited in its ability to control an individual's behavior by what that person has to lose (the size of the sanction) if he or she deviates from the social norm's 
prescriptions. Since ostracism is simply the exclusion of an individual from the community, the benefits of community membership and the costs of ostracism are one and the same. Thus, if an individual gains little or nothing from community membership (in our model, the agents with the lowest status), the threat of ostracism is of little importance; consequently, a social norm consistent with optimizing behavior must allow behavior that is essentially self-interested for such an individual. However, an individual who benefits substantially from community membership-a high status individual-can more easily be induced to engage in behavior that is not self-interested. Consequently, different classes of society may exhibit different modes of conduct because the prevailing social norm distinguishes among them on the basis of status.

Our goal is to understand how class structures that arise within a social norm can affect behavior. If class is to play a meaningful role in understanding behavior, it cannot be simply as a categorization of people into groups. To define the "class of low income people" as, say, those people with incomes below half of the median income has no effect on how those people behave. A change that assigned more or fewer people to the named "class" would have no effect on how any agent behaved or on what he or she received in equilibrium. To be a useful concept, classes should be more than instruments to describe equilibria. The model we present will allow us to ask-and answerquestions such as "What is the difference between equilibria when there are classes in a society and when there are no classes?" and "How different would the consumption of an agent be if he or she were moved from one class to another?"

The possibility that classes can ameliorate inefficiencies requires the existence of multiple equilibria. Standard descriptions of economies are underspecified: A full description of the economic data, including preferences, endowments, and technological possibilities, is not sufficient to uniquely determine the outcome that arises. Associated with the equilibrium that does arise are social in- 
stitutions not normally considered a part of the economic data of the problem (for example, norms or customs, political and social institutions, etc.). We analyze a model in which there are multiple equilibria and a subset of the equilibria are naturally thought of as having a class structure. The equilibria in this subset qualitatively differ from equilibria with a single class. For example, in an equilibrium with two classes, there are no interactions between members of one class and another, yet the behavior of individuals in the upper class qualitatively differs from what it would be in the absence of the lower class. The mere existence of the lower class changes the kinds of behavior of individuals in the upper class that can be supported in an equilibrium. Further, in answer to the second question in the previous paragraph, in a two class equilibrium, an individual who is moved from the upper class to the lower will have his or her utility decreased.

We emphasize that our model integrates the notion of class into a traditional economic model. Individuals do not receive utility from being in one class or another; they care directly only about the goods they consume. Any concern about class membership is instrumental: people care about class only to the extent that, in equilibrium, class affects an individual's opportunities.

Our starting point is the model of social norms we introduced in Cole, Mailath, and Postlewaite [2], hereafter CMP. We analyzed in that paper a simple multi-generation model in which parents could increase their savings in order to improve their children's matching prospects. When all families do this, their efforts offset each other, leaving all parents worse off than if they had not engaged in this bequest competition. It is not, however, an equilibrium for all families to simply forgo the effort, because if no other families increase their savings, any single family benefits by doing so. This competitive over-saving is the self-interested behavior in the context of CMP. The social competition is essentially a prisoners' dilemma. We showed in that paper that in addition to the equilibrium in which this competitive over-saving behavior occurs, there may exist an equilibrium 
in which this socially suboptimal behavior of over-saving was suppressed. This second equilibrium was supported by an aristocratic social norm that prescribed matching in a way that was unaffected by savings and imposed sanctions on any family whose son married better than prescribed by the social norm.

The equilibrium in which this social competition is not suppressed is similar to the repeated "not cooperate" equilibrium in the standard repeated prisoners' dilemma game. ${ }^{1}$ In the repeated "not cooperate" equilibrium, agents play the dominating action in each period and so maximize stage game payoffs, yielding a Pareto inefficient outcome. Just as this equilibrium of the prisoners' dilemma game is robust to the number of repetitions, the equilibrium in our model in which social competition is not suppressed is robust. It is the limit of the unique equilibria of the corresponding finite horizon models. Other equilibria, in contrast, require some degree of inter-generational enforcement, since at times a woman must be given an incentive to reject an offer from a suitor who is wealthier than the woman's prescribed match. Such behavior can only be optimal if deviations from the social norm's prescription result in future negative consequences (e.g., a loss of status resulting in the sons of deviating parents being unable to match with any but the poorest women, as prescribed in the aristocratic social norm). Hence such equilibria can never be obtained as the limit of the sequence of equilibria for finite horizon economies.

An equilibrium in which social competition has been completely suppressed has a source of fragility, due to the heterogeneity of agents, not exhibited in the cooperative equilibrium of a standard prisoners' dilemma. In our model, the equilibrium in which competition is suppressed prescribes a punishment for a family that deviates from the social norm-future male offspring

\footnotetext{
${ }^{1} \mathrm{CMP}$ did not show uniqueness of the equilibria in which the over-saving is not suppressed. However, there is only one equilibrium with the robustness property described below.
} 
in this line will be matched with the poorest women of their generation. This punishment is of arbitrarily small concern to couples at the lower end of the status distribution: their male offspring will be matched with women who are close to the poorest even when the norm's prescriptions are followed. As a result, the punishment may be insufficient to deter deviations by such couples. The class of equilibria in which social competition is only suppressed among the wealthier families avoids the difficulty of enforcing prescribed behavior among those elements of the society with "nothing to lose."

\section{The CMP Model}

There are two types of one-period-lived agents, men and women. The agents are to be matched into pairs with each pair having two offspring, one male and one female. In addition to the matching decision, agents make standard economic decisions: what to consume and/or what to invest. Agents care about the economic characteristics of potential mates.

Men and women are treated asymmetrically in two respects in order to reduce the technical complexity of the model. First, women are endowed with a non-traded, non-storable good, while men inherit a second, storable good which we call capital. Women are indexed by $j \in[0,1]$ and woman $j$ is endowed with $j$ units of the non-traded good. The men are indexed by $i \in[0,1]$ and are endowed with differing amounts of capital in the first period.

Second, only the welfare of the male offspring enters the pair's utility function. We normalize so that a male offspring inherits his father's index, and we will refer to man $i$, his son, his son's son, and so on, as family line $i$. Consequently, parents will make bequests only to their male offspring.

Men and women have identical utility functions defined over joint consumption of a matched pair's bundle given by $u(c)+j$, where $c$ and $j$ are, respectively, the quantities of the male and the 
female goods. The utility derived from the male good is given by a constant relative risk aversion utility function with degree of risk aversion $\gamma ; u(c)=(1-\gamma)^{-1} c^{1-\gamma}$ for $\gamma \neq 1$, and $u(c)=\ln c$ for $\gamma=1$. Finally, the utility level of their male descendants also enters linearly into each parent's utility function, discounted by $\beta \in(0,1)$.

The problem facing a couple is, given their wealth (determined by the bequest from the male's parents), how much to consume and how much to bequeath to their son. Their son values the bequest for two distinct reasons. First, it affects the amount he and his descendants can consume, and second, the bequest may affect the quality of his mate. To the extent that their son's match is affected, parents will have an additional incentive to leave a larger bequest than they otherwise would.

Matching is voluntary with men knowing the distribution of bequests and women's endowments. Men prefer wealthier women (that is, those with higher values of $j$ ), all else equal. It may be, however, that successfully matching with a wealthy woman has adverse implications for the matching prospects of male descendants. For example, they may be punished if their parents deviated from prescribed behavior. Women also prefer wealthier mates, all else equal. Here, also, matching with a wealthy man can have adverse implications for descendants' prospects if this violates the prescriptions of the social norm. ${ }^{2}$

In each period, matches are determined by the following process: ${ }^{3}$ Each man can make an offer to match with (propose to) any woman. Each woman then chooses the most attractive offer if more than one proposal is received. No further offers are made; in particular, there are no

\footnotetext{
${ }^{2}$ Note that since wealth is passed through the sons, the male offspring from such a match may also be wealthier (depending on the bequest decision).

${ }^{3}$ For the case of a finite number of players, the set of subgame perfect equilibrium matchings is precisely the set of stable matchings (Roth and Sotomayer [9]).
} 
counterproposals by women to men and no offers from men reacting to the offers of other men. If only one proposal is received by a woman, then that proposal is accepted. If a man's proposal is unsuccessful, he is unmatched. 4 Similarly, if a woman does not receive any proposals, she is unmatched. A matching is a function $m:[0,1] \rightarrow[0,1] \cup\{\emptyset\}$ that is measure-preserving and one-to-one on $m([0,1]),{ }^{5}$ where $m(i)=j \in[0,1]$ is $i$ 's match and $m(i)=\emptyset$ indicates that $i$ is not matched. We say that $m$ describes a stable matching if, taking into account future consequences, no pair would prefer to be matched with each other rather than with their current match.

Agents use capital for current consumption and savings. Output is produced according to

$$
c=A k-k^{\prime}
$$

where $k$ is the initial endowment capital, $c$ is first period consumption, $k^{\prime}$ is second period capital, and $A>1$ is a constant. To insure that the capital stock grows over time, but family line payoffs remain bounded, we assume that $1<A \beta<A^{\gamma}$. We will use interchangeably the terms output and wealth. The initial endowment of capital for men in the first period, $k_{0}:[0,1] \rightarrow \Re_{+}$, is a continuous and nondecreasing function of $i$.

\subsection{The Exogenous Matching Benchmark}

An important benchmark is the case of exogenous matching. With exogenous matching, families solve a simple decision problem with regard to their consumption and savings levels in each period. The solution to this problem describes savings behavior when competitive over-saving to influence

\footnotetext{
In a model with a finite number of agents, we can simply assign the woman with the lowest endowment to the unsuccessful man and reassign the other women, maintaining the order.

${ }^{5}$ That is, for all measurable subsets $A \subset[0,1], m^{-1}(A)$ is measurable and $\lambda\left(m^{-1}(A)\right)=\lambda(A)$, where $\lambda$ denotes Lebesgue measure.
} 
matching has been suppressed by fiat.

If $\left\{j_{t}\right\}_{t=0}^{\infty}$ is the sequence of matches for family line $i$, then family line $i$ solves $^{6}$

$$
\max _{\left\{k_{t}\right\}} \sum_{t=0}^{\infty} \beta^{t}\left\{u\left(A k_{t}-k_{t+1}\right)+j_{t}\right\}
$$

$$
\text { subject to } k_{0}=k_{0}(i) \text { and } A k_{t} \geq k_{t+1} \text {. }
$$

This is a standard dynamic programming problem with unique solution $\left\{k_{t}^{*}\right\}_{t=0}^{\infty}$, where $k_{0}^{*}=k_{0}(i)$, $k_{t}^{*}=\left(1-\lambda^{*}\right) A k_{t-1}^{*}$, and $\lambda^{*}=1-\left(A^{1-\gamma} \beta\right)^{1 / \gamma}$. The discounted value from consumption is $V^{*}(k)=$ $\left(\lambda^{*} A k\right)^{1-\gamma} /\left[(1-\gamma) \lambda^{*}\right]$ if $\gamma \neq 1$ and $V^{*}(k)=(1-\beta)^{-2}\{(1-\beta) \ln (1-\beta)+\beta \ln \beta+\ln A+(1-\beta) \ln k\}$ if $\gamma=1$. With exogenous matching, there is no strategic interaction between family lines, and each family line makes bequest decisions solely motivated by intertemporal consumption considerations.

\section{Single Class Equilibria}

A complete description of behavior (i.e., a strategy profile) in CMP is a specification of bequest and matching behavior for each agent of all generations after all possible histories. For a given ordering of men, a man's status is his rank in that ordering. We assume that a man's status determines the quality of his match, if all agents follow society's prescribed rules. A man's status (rank) can depend upon, among other things, his own wealth and the status and match of his parents. A social norm is a status assignment rule that determines in each generation each man's status as a function of the behavior of previous generations. An equilibrium is a social norm together with a

\footnotetext{
${ }^{6}$ We are assuming here, as in CMP, that the first member of the family line believes that the descendants will make the consumption-investment decisions that that member would choose if it was possible to dictate their choices. Since Bellman's principle of optimality applies, we have described a subgame perfect equilibrium of the game of consumption-investment choices with a countably infinite number of players (one player for each generation). It is possible that there are other equilibria, which we don't discuss.
} 
specification of matching and market decisions such that female $j$ matches with male of status $j$ and no agent wishes to deviate.

\subsection{Wealth-is-status equilibria}

We first describe the unique behavior consistent with equilibrium if there is a finite horizon. We call the social norm that supports this behavior the wealth-is-status social norm. The characteristics of the equilibria associated with this social norm when there is an infinite horizon are explored in more detail in CMP.

To fix ideas, we first consider the two period case, in which parents are exogenously matched in the first period. ${ }^{7}$ In the second (and last) period, matching occurs and each man (together with spouse if he is matched) consumes his bequest. In the first period, parents decide on the level of bequest to their sons (and so their own consumption). Since, in the second period, women accept the wealthiest suitor (the only consideration in women's, and men's, matching decisions is current consumption), matching is necessarily positively assortative. Thus, if $F$, the induced distribution of wealth in the second period by first period bequest decisions, is strictly increasing, female $j \in[0,1]$ is matched with the male with wealth $s$ satisfying $j=F(s)$. It is worth emphasizing at this point that parents can guarantee a match for their son of a woman with endowment arbitrarily close to $j$ by bequeathing $A^{-1} F^{-1}(j)$ (recall (2.1)). The problem for couple $i$ in the first period is to choose the bequest $k \in\left[0, A k_{0}(i)\right]$ to maximize

$$
u\left(A k_{0}(i)-k\right)+\beta u(A k)+\beta F(A k) .
$$

\footnotetext{
${ }^{7}$ As will be clear shortly, this is without loss of generality.
} 
The first order condition is ${ }^{8}$

$$
-u^{\prime}\left(A k_{0}(i)-k\right)+\beta A u^{\prime}(A k)+\beta A F^{\prime}(A k)=0 .
$$

Note in particular that the level of the bequest that solves this problem will be strictly larger than the value of $k$ that solves $u^{\prime}\left(A k_{0}(i)-k\right)=\beta A u^{\prime}(A k)$, i.e., than the optimal bequest when matching is exogenous (in other words, in the absence of matching considerations). This is precisely the competitive over-saving generated by the competition for spouses (of the sons by the parents) discussed above.

Except in one case, in the finite horizon model there is a unique equilibrium associated with a given initial distribution of capital, and it is characterized by competitive over-saving to influence matching. The exception is the case in which the support of the initial endowment distribution of capital includes zero. In this case, while there will be an equilibrium with over-saving, there may also exist other equilibria. Any equilibrium in which over-saving is suppressed requires that the distribution of individuals' choices depend on the actions of individual agents, which we find implausible in a model with a continuum of agents. The wealth-is-status equilibrium of the infinite horizon economy can be obtained as the limit of a sequence of (the plausible) equilibria of a sequence of finite horizon economies in which the horizon goes to infinity. The finite horizon equilibria of this model are examined in detail in Appendix A.

The wealth-is-status social norm prescribes that if a woman receives multiple proposals, the proposal from the wealthiest man is accepted (if there is a tie, then the woman flips a coin). Since this implies that there are no consequences from doing otherwise, it is clearly optimal for a woman

\footnotetext{
${ }^{8}$ We show in Appendix A that $F$ will indeed be strictly increasing and differentiable.
} 
to follow the prescription. The equilibrium matching thus depends only on the men's capital endowments of that period (which are determined by their parents' bequests). In equilibrium, the wealthiest man will match with the wealthiest woman, and so on. A man's match in period $t$ depends, then, only on his relative position in the capital distribution of period $t$. A wealth-is-status equilibrium is a description of consumption-bequest decisions consistent with the wealth-is-status social norm.

To derive these consumption-bequest decisions, suppose that the bequest of capital in period $t$ is given by $k_{t}:[0,1] \rightarrow \Re_{+}$, where $k_{t}$ is a strictly increasing function. Further, suppose that in equilibrium all agents consume in such a way that the next period capital bequest is given by $k_{t+1}$, also strictly increasing and differentiable on $(0,1)$, so that the match in period $t+1$ is $m(i)=i$. Consider family line $i$ 's choice of bequest in period $t$. By increasing the bequest from $k_{t+1}(i)$ to an amount $k$ in the next period, the man of index $i$ will succeed in matching with any woman such that $j<k_{t+1}^{-1}(k)$. If we let $m_{t+1}(k)=k_{t+1}^{-1}(k)$ denote the supremum of $i$ 's match as a function of the bequest received, then the problem facing an agent $i$ in period $t$ who inherits $k_{t}$ amount of capital is

$$
\max _{0 \leq k_{t+1} \leq A k_{t}} u\left(A k_{t}-k_{t+1}\right)+m_{t}\left(k_{t}\right)+\beta W_{t+1}\left(k_{t+1}\right) \equiv W_{t}\left(k_{t}\right)
$$

If $W_{t+1}$ is differentiable, the first order condition on bequests is given by $u^{\prime}\left(A k_{t}-k_{t+1}\right)=$ $\beta W_{t+1}^{\prime}\left(k_{t+1}\right) .>$ From the envelope condition, $W_{t+1}^{\prime}\left(k_{t+1}\right)=A u^{\prime}\left(A k_{t+1}-k_{t+2}\right)+m_{t+1}^{\prime}\left(k_{t+1}\right)$. Thus, we get the following difference equation which describes a family line's optimal capital accumulation decision:

$$
u^{\prime}\left(A k_{t}-k_{t+1}\right)=\beta\left\{A u^{\prime}\left(A k_{t+1}-k_{t+2}\right)+m_{t+1}^{\prime}\left(k_{t+1}\right)\right\}
$$

Wealth-is-status equilibria exist for all $\gamma$ (CMP and [4]). While there is no guarantee of unique- 
ness in the infinite horizon economy, there is only one wealth-is-status equilibrium that can be approximated by the unique (robust) equilibrium of the finite horizon games (see Appendix A). Let $\left\{k_{t}(i)\right\}$ denote family line $i$ 's sequence of bequests in a wealth-is-status equilibrium. Then we have the following (from CMP):

Proposition 3.1. For all family lines $i$ and all $t \geq 0, k_{t}(i) \geq k_{t}^{*}(i)$, with a strict inequality for all but a set of families of measure 0 .

Proposition 3.2. In a wealth-is-status equilibrium, if $k_{0}(i)>k_{0}\left(i^{\prime}\right)$, then for all $t$, the optimal level of capital in period $t$ for agent $i$ and $i^{\prime}$ satisfies $k_{t+1}(i)>k_{t+1}\left(i^{\prime}\right)$.

These two propositions illustrate the inefficiency of wealth-is-status equilibria. The first proposition states that for all but a negligible set of families, the bequest choices are higher than they would prefer had there been no competition for future mates, while the second proposition states that the net effect of all families' decisions cancels out. Despite the fact that all families are increasing their savings to improve their relative position, in equilibrium, no family moves up or down in the wealth ranking over time.

Thus, in any period every family line (except the poorest) would be strictly better off if the identical matching were imposed exogenously, so that all families reduce their bequest choices in that and all future periods to $k_{t}^{*}$, the levels that solve (2.2). Note that this comparison only necessarily holds for the current generation. The comparison for future generations is more delicate, since the future cost of engaging in competitive over-saving may be outweighed by the current benefit of receiving a larger bequest. As we pointed out in the introduction, the problem facing the families in any single generation is essentially a prisoners' dilemma game: any single family has an incentive to increase its savings whether or not other families do so, but the result of all families doing this 
is to make all families worse off than if none did so.

\subsection{Aristocratic equilibria}

A social norm in which status was unaffected by bequest decisions would eliminate this competitive over-saving. If such a social norm were followed, families would no longer have an incentive to oversave. We analyzed one such social norm, which we called the aristocratic social norm, in CMP. In the aristocratic social norm, a man's status is inherited; that is, his status is the same as his father's as long as his father matched appropriately. In the initial period, there is an exogenously given status assignment. An aristocratic equilibrium consists of the above status assignment rule, consumptionbequest decisions, and matching behavior for the agents such that each man is voluntarily matched with the woman whose endowment equals the man's status; if a man matches with a woman with an endowment not equal to his status, the family line from that point on has zero status (and so all future matches are with women of zero endowment). Lastly, no woman with positive endowment finds it profitable to match with a zero status man when either that man's family line has always had zero status or the status is newly acquired. ${ }^{9}$

The aristocratic social norm described above prescribes a specific behavior and a sanction if that behavior is violated, namely, that the violating family has its status reduced to zero. We can imagine alternative sanctions as well, for example, ostracism. If we interpret ostracism as the complete separation from the rest of society, ostracism would result in the extinction of the family line after one period (unless we allowed for marriage within the family). In this view, ostracism is essentially equivalent to death. A less extreme interpretation of ostracism is that it does not lead to

\footnotetext{
${ }^{9}$ We are only requiring that it be optimal for a woman to follow status on the equilibrium path and for one generation off the equilibrium path. This issue is discussed in detail in CMP.
} 
extinction of the family line, so that the male line can consume the infinite sequence of consumption $\left\{c_{t}\right\}$. Thus, if ostracized, a family line solves (2.2) and has total discounted utility of $V^{*}(k)$. This is also the total discounted utility of a family line with zero status. Moreover, since in equilibrium, no woman with positive endowment finds it profitable to match with a zero status man when that status is newly acquired, it is also not profitable for her to match with an ostracized man. Thus, ostracism (in its less extreme form) is equivalent to the loss of status specified in the aristocratic equilibrium. ${ }^{10}$ It is worth noting that this is the most severe punishment available consistent with property rights that preclude confiscation of endowments. Of course, more severe sanctions can be constructed by taxing or expropriating the wealth of family lines.

If everyone obeys the aristocratic social norm (i.e., the status assignment rule and matching contingent on status), then a male from family line $i$ will always match with the female endowed with $j=i$, irrespective of his wealth. A family line is punished by having its status, and hence match, set to zero forever if one of the men in the line marries a woman other than the one prescribed by this rule.

If all families follow the prescriptions of the aristocratic social norm, bequests will be given by $k_{t}^{*}$, the solution to (2.2), and so there is a zero first order cost to increasing their bequest. Thus, in order for the aristocratic social norm to be consistent with equilibrium, it is necessary that there be no more than a second order gain from a small increase in bequests. In order for a deviation by family $i$ to be successful (in the sense of improving the quality of the match of their son), three deviations are necessary. First, the parents must make a bequest above $k_{t}^{*}(i)$ (otherwise their son's match would be $j=i$ even if women accepted the wealthiest suitor). Second, the son must

\footnotetext{
${ }^{10}$ This equivalence does not hold if the distribution of women's endowments is bounded away from zero.
} 
make a proposal to a higher ranked woman $j>i$, and finally, the offer must be accepted. ${ }^{11}$ The trade-off facing the parents in family line $i$ is whether the one period increase in quality of match is sufficient to outweigh the permanent future loss of status (valued at $\beta^{2} i /(1-\beta)$ ) as well as the one period distortion in bequest behavior (that is of zero first order cost). The trade-off for the son is similar, although the loss of status occurs one period earlier and there is no distortion of bequest behavior. Finally, the trade-off for the potential spouse is the comparison between the increase in consumption and loss of status. Recall that, by assumption, if the potential spouse receives a higher utility (including future costs or benefits) from the offer of the deviating male, then she will accept it.

If both family line $i$ and female $j$ (and consequently $j$ 's son) have low status, then the loss of status is not a severe threat, which makes the existence of aristocratic equilibria delicate. For example, if $k_{0}(0)>0$, then aristocratic equilibria cannot exist. To see this, let $L_{t}(j)$ be the capital level that leaves the woman indifferent between matching with the man of status $j$ with capital $k_{t}(j)$ and maintaining the current status for her son and matching with a man with capital $L_{t}(j)$ and having her son receive zero status. If the woman does match with the latter, the status of the man that the woman deviates to is irrelevant since her offspring will have zero status. Thus, the capital level $L_{t}(j)$ is described by

$$
V^{*}\left(L_{t}(j)\right)+j=V^{*}\left(k_{t}(j)\right)+\frac{j}{1-\beta}
$$

\footnotetext{
1IThe necessity of the first deviation follows from our assumption that the original assignment of status is that family line $i$ has status $j=i$, so that if bequest behavior and matching is in accordance with the candidate equilibrium, then matching will be positively assortative. If aristocratic equilibria exist, additional aristocratic-type equilibria can be constructed in which the status assignment deviates somewhat (particularly at higher wealth levels) from the relative position in the initial wealth distribution. In these other aristocratic equilibria, family $i$ may be successful in a deviation after only two deviations (if the son already has wealth greater than that of the intended match for some $j>i)$.
} 
Note that $L_{t}(j)$ exceeds $k_{t}(j)$ by an amount that compensates for the value of lost status. It is worth noting here that $L_{t}(j)$ is close to $k_{t}(j)$ for $j$ close to zero. Consider now the bequest decision of family line $i$ in period $t-1$. Bequeathing $L_{t}(j)$ will improve their son's match, but at a cost of reduced consumption today as well as lower status after two generations. Bequeathing $k_{t}(i)$ yields a (weakly) higher payoff than $L_{t}(j)$ if

$$
V^{*}\left(k_{t-1}(i)\right)+i /(1-\beta) \geq u\left(A k_{t-1}(i)-L_{t}(j)\right)+i+\beta j+\beta V^{*}\left(L_{t}(j)\right)
$$

This inequality holds with equality when $i=j=0$. While the left hand side is independent of $j$, the right hand side is strictly increasing in $j$ (its derivative with respect to $j$ is $\beta+\left(\beta\left(V^{*}\right)^{\prime}-u^{\prime}\right) L_{t}^{\prime}=$ $\beta>0$ at $i=j=0$ ). Thus, the inequality is violated for $i$ and $j$ small, and aristocratic equilibria do not exist when $k_{0}(0)>0 .{ }^{12}$

The crucial feature is that, when $k_{0}(0)>0$, the family line with zero status can attract a significantly better mate for their son by bequeathing enough. Similarly, all family lines with sufficiently low status can also attract significantly better mates for their sons than they would by following the prescription of the social norm. Low status families gain little by following the social norm and, consequently, have little to lose if they deviate from its prescriptions. When $k_{0}(0)>0$, these families have the wealth to deviate from the norm's prescriptions in ways that lead to net benefits.

Aristocratic equilibria may exist when $k_{0}(0)=0$. In this case, low status family lines cannot attract significantly better mates for their sons, because low status family lines simply don't have

\footnotetext{
${ }^{12}$ More generally, suppose that the value of a match with female $j$ is $v(j)$ (rather than $j$ ). The above argument applies as long as $v^{\prime}(0)>0$. Aristocratic equilibria will exist when $k_{0}(0)>0$ for some specifications of $v$ (this would, of course, require that $v^{\prime}(0)=0$ ).
} 
sufficient wealth to induce a better mate to deviate from her prescribed match. Phrased differently, any family with sufficient wealth to induce a deviation by a significantly better quality match has sufficient status that its loss will deter a deviation. However, even when $k_{0}(0)=0$, the existence of aristocratic equilibria is tenuous. ${ }^{13}$ In [4], we provide a sufficient condition for the existence of aristocratic equilibria, when $u(c)=\ln c$ and $k_{0}(i)=\kappa i$, for some $\kappa>0 .{ }^{14}$

In summary, while wealth-is-status equilibria exist under standard regularity conditions, aristocratic equilibria exist only under quite restrictive conditions. Eliminating the incentive to over-save is impossible in most circumstances. However, while a social norm may not be able to eliminate the incentive to over-save, it can ameliorate the incentive to over-save by dividing society into groups, solving the problem in some but not all groups. The division of society into groups which differ in the degree to which social competition is controlled also introduces an additional control instrument: the threat of reassigning deviators in a group to another group in which the competition has not been controlled.

\section{Equilibria with Class Systems}

In this section we will explore social arrangements that ameliorate inefficient savings competition. The social norms we examine divide society into groups, attempting to restrict competition in some groups, but not all. Individuals in groups in which the competition is eliminated will face the

\footnotetext{
${ }^{13}$ The condition in CMP for the existence of aristocratic equilibria was subsequently shown to be vacuous by Landsberg [7].

${ }^{14}$ Landsburg [7] provides a condition (condition 1) that avoids the nonexistence problem by guaranteeing a mass of males who have no wealth and consequently cannot deviate from the social norm. This creates a uniform, bounded away from zero per period punishment that can be imposed on all potential deviators with a nontrivial decision. Furthermore, since the punishment entails that all future males in this line will be affected in this way, the cost of this punishment can be made arbitrarily large by choosing a discount factor sufficiently close to 1 . This argument has the flavor of the folk theorem in repeated games and relies on the existence of a sufficiently large punishment that can be imposed on deviators to ensure concurrence with a prescribed equilibrium.
} 
threat of being ejected from the group if they deviate from the norm's prescriptions. We interpret the partition of society into different groups as constituting different social classes when there is a qualitatively different determination of status between the groups.

The first social norm we study, in Section 4.1, is an aristocratic two-class equilibrium: the population is divided into two groups, with the bottom group governed by the wealth-is-status social norm and the upper group governed by the aristocratic social norm, modified so that if there is a deviating match, the resulting family line is relegated to the lower group. Hence, oversaving is eliminated in the upper class, but not in the lower class. The question of existence of an equilibrium consistent with this social norm is delicate; we provide necessary and sufficient conditions for existence only in terms of the endogenous consumption value functions (Proposition 4.1).

Section 4.2 describes and gives sufficient conditions on exogenous parameters for the existence of a variant of this two-class social norm. It differs from the aristocratic two-class social norm in that the matching is random in the upper class. Even when the aristocratic two-class social norm does not exist, the variant social norm eliminates over-saving in the upper group.

Finally, in Section 4.3, we combine elements of the previous two social norms to describe a three-class social norm, in which the bottom class follows wealth-is-status, the middle class follows random matching but is not over-saving, and the upper class is aristocratic and is not over-saving. The conditions for existence of the three-class equilibrium are similar to that for the randomized two-class equilibrium. 


\subsection{An aristocratic two-class equilibrium}

We define an aristocratic two-class status social norm as follows. Given a designated index $i_{l} \in$ $(0,1)$, we divide both men and women into two groups, $\left[0, i_{l}\right]$ and $\left(i_{l}, 1\right]$, called, respectively, the lower group and the upper group. ${ }^{15}$ Status for men in the lower group is determined by wealth, and matching in this group is as in the wealth-is-status social norm: the woman with index $i$ marries the man with status $i$. Male $i$ in the upper group has status $i$ (and so matches with female $j=i$ ) as long as the men in that family line have followed the prescribed matching. If there is a deviation by a man or a woman in the upper group, then male descendants are assigned thereafter to the lower group.

If the women in the upper group reject all offers from men in the lower group, the men and women in the lower group behave as a separate society following the wealth-is-status social norm. Let $\left\{\hat{k}_{t}\left(i_{l}\right)\right\}_{t=1}^{\infty}$ be the sequence of bequests by family line $i_{l}$ in a wealth-is-status equilibrium and $\left\{\hat{V}_{t}\left(\hat{k}_{t}\left(i_{l}\right)\right)\right\}$ be the sequence of values of the discounted utility streams from consumption for family line $i_{l}$. The existence of this lower group, with its inefficient savings decisions, creates the possibility that the simple threat of relegation to the lower group may be sufficient to deter deviation. ${ }^{16}$

Initial wealth, $k_{0}$, is nondecreasing in index; hence, agents in the upper group (the "aristocrats") are initially at least as wealthy as agents in the lower group. Thus, in the first period, $\hat{V}_{1}\left(\hat{k}_{1}(i)\right) \leq$ $\hat{V}_{1}\left(\hat{k}_{1}\left(i_{l}\right)\right)<V^{*}\left(k_{1}^{*}\left(i^{\prime}\right)\right)$ for all $i \leq i_{l} \leq i^{\prime}$, and so there is a loss of consumption utility from being relegated to the lower group (and for this reason, there is also no possible gain from deviating for a woman in the upper group). However, the lower group family lines are accumulating wealth at

\footnotetext{
${ }^{15}$ It simplifies discussion to place $i^{\prime}$ in the lower group. Nothing substantive hinges on the choice of group that $i^{\prime}$ belongs to.

${ }^{16} \mathrm{It}$ is also worth noting that the savings behavior of family lines $i<i_{l}$ is independent of the value of $i_{l}$. The level of bequests by family line $i$ is determined by the need to bequeath more than the family lines below $i$. Specifically, the bequests are determined by an initial value problem with an initial value at 0 (see Appendix A).
} 
a faster rate than the upper group family lines, and $k_{0}$ is continuous, so lower group men will be wealthier than men in the upper group in the next period; i.e., $\hat{k}_{2}\left(i_{l}\right)>\inf _{i^{\prime} \backslash_{i_{l}}} k_{2}^{*}\left(i^{\prime}\right)=k_{2}^{*}\left(i_{l}\right)$. It is not clear how $\hat{V}_{t}\left(\hat{k}_{t}\left(i_{l}\right)\right)$ and $V^{*}\left(k_{t}^{*}\left(i^{\prime}\right)\right)$ rank for $t \geq 2$ and $i^{l}>i_{l}$. It is possible that some lower group family lines asymptotically become extremely wealthy relative to family lines in the upper group.

A necessary condition for the aristocratic two-class social norm to be consistent with equilibrium is that $\hat{V}_{t}\left(\hat{k}_{t}\left(i_{l}\right)\right) \leq V^{*}\left(k_{t}^{*}\left(i_{l}\right)\right)$ for all $t$. To see this, suppose that $\hat{V}_{t}\left(\hat{k}_{t}\left(i_{l}\right)\right)>V^{*}\left(k_{t}^{*}\left(i_{l}\right)\right)$ for some $t$. Then, for $i^{\prime}$ close to $i_{l}, \hat{V}_{t}\left(\hat{k}_{t}\left(i_{l}\right)\right)>V^{*}\left(k_{t}^{*}\left(i^{\prime}\right)\right)$. A deviating offer by male $i_{l}$ to a female $i^{\prime}>i_{l}$ is profitable for male $i_{l}$ if accepted. But the deviating offer is accepted if

$$
\hat{V}_{t}\left(\hat{k}_{t}\left(i_{l}\right)\right)-V^{*}\left(k_{t}^{*}\left(i^{\prime}\right)\right)>\frac{\beta\left(i^{\prime}-i_{l}\right)}{(1-\beta)}
$$

which holds for $i^{\prime}$ close to $i_{l}$.

Moreover, this necessary condition is almost (but not quite) sufficient. Certainly, if $\hat{V}_{t}\left(\hat{k}_{t}\left(i_{l}\right)\right) \leq$ $V^{*}\left(k_{t}^{*}\left(i_{l}\right)\right)$ for all $t$, then no female in the upper group will accept an offer of $k \leq \hat{k}_{t}\left(i_{l}\right)$ from a male in the lower group-it involves both a loss of status and a reduction in family line consumption utility. However, we must also rule out the possibility that, for example, the parents in family line $i_{l}$ in period $t$ bequeath $k>\hat{k}_{t}\left(i_{l}\right)$ in order to offer a consumption utility of strictly more than $\hat{V}_{t}\left(\hat{k}_{t}\left(i_{l}\right)\right) \cdot{ }^{17}$

Suppose $\hat{V}_{t}\left(\hat{k}_{t}\left(i_{l}\right)\right)=V^{*}\left(k_{t}^{*}\left(i_{l}\right)\right)$ in period $t$. Generation $t-1$, by bequeathing strictly more than $\hat{k}_{t}\left(i_{l}\right)$ to their son, can guarantee him a better match than $i_{l}$. The increase in the index of the female that male $i_{l}$ can induce to deviate, however, is of the same order as the increase in the bequest over

\footnotetext{
${ }^{17}$ If any family line in the lower group has a profitable deviation, then so does family line $i_{l}$.
} 
$\hat{k}_{t}\left(i_{l}\right)$. Qualitatively, this is the same trade-off that faces family line $i_{l}$ in the wealth-is-status social norm. Note in particular, that in the wealth-is-status equilibrium, it is not optimal for generation $t-1$ to increase their bequest from $\hat{k}_{t}\left(i_{l}\right)$ to any $k>\hat{k}_{t}\left(i_{l}\right)$, even though their son's spouse's index increases from $i_{l}$ to $\left(\hat{k}_{t}\right)^{-1}(k)$. Let $i(k)$ be the highest index spouse from the upper group that $i_{l}$ can induce to deviate after receiving a bequest of $k$. Then, for $k$ close to $\hat{k}_{t}\left(i_{l}\right)$ (so that it is optimal to consume all of $A k-\hat{k}_{t+1}\left(i_{l}\right)$ in one period), $i(k)$ satisfies

$$
u\left(A k-\hat{k}_{t+1}\left(i_{l}\right)\right)+i(k)+\beta \hat{V}_{t+1}\left(\hat{k}_{t+1}\left(i_{l}\right)\right)+\frac{\beta i_{l}}{1-\beta}=V^{*}\left(k_{t}^{*}(i(k))\right)+\frac{i(k)}{1-\beta}
$$

By construction, generation $t-1$ is indifferent between the bequest-match pair $\left(\hat{k}_{t}\left(i_{l}\right), i_{l}\right)$ and the pair $\left(k,\left(\hat{k}_{t}\right)^{-1}(k)\right)$, where $k$ is arbitrarily close to $\hat{k}_{t}\left(i_{l}\right)$. Thus, if $i(k)>\left(\hat{k}_{t}\right)^{-1}(k)$ for $k$ larger than, but in a neighborhood of, $\hat{k}_{t}\left(i_{l}\right)$, then generation $t-1$ will deviate. While we have been unable to verify that this inequality holds, the structure of the wealth-is-status equilibrium suggests that it does. ${ }^{18}$

$$
\begin{aligned}
& { }^{18} \text { Since } i\left(\hat{k}_{t}\left(i_{l}\right)\right)=\left(\hat{k}_{t}\right)^{-1} \hat{k}_{t}\left(i_{l}\right)=i_{l}, \text { if } \\
& \left.\frac{d i(k)}{d k}\right|_{k=\hat{k}_{t}\left(i_{l}\right)}>\left.\frac{d\left(\hat{k}_{t}\right)^{-1}}{d k}\right|_{k=\bar{k}_{t}\left(i_{l}\right)},
\end{aligned}
$$

then the inequality holds. Now,

$$
\left(\beta+(1-\beta) d V^{*} / d k \cdot d k^{*} / d i\right) d i(k) / d k=(1-\beta) A u^{\prime}\left(A k-\hat{k}_{t+1}\left(i_{i}\right)\right)
$$

while (3.3) implies (since $m_{t}(k)=\hat{k}_{t}^{-1}(k)$ and $k=\hat{k}_{t}(i)$ in equilibrium) that

$$
\frac{d\left(\hat{k}_{t}\right)^{-1}}{d k}=\beta^{-1}\left(u^{\prime}\left(A \hat{k}_{t-1}(i)-\hat{k}_{t}(i)\right)-\beta A u^{\prime}\left(A \hat{k}_{t}(i)-\hat{k}_{t+1}(i)\right)\right) .
$$

For sufficiently large wealth, $d i(k) / d k$ and $\beta^{-1}(1-\beta) A u^{\prime}\left(A k-\hat{k}_{t+1}\left(i_{l}\right)\right)$ have almost the same slope. Thus, the inequality holds if $A u^{\prime}\left(\hat{c}_{t}\right)>u^{\prime}\left(\hat{c}_{t-1}\right)$, where $\hat{c}_{t}=A \hat{k}_{t}(i)-\hat{k}_{t+1}(i)$. For $\gamma>1$, this is equivalent to $A^{1 / \gamma}>\hat{c}_{t} / \hat{c}_{t-1}$. This condition will be met if $\hat{c}_{t}$ is approximately equal to $\hat{c}_{t-1}$. Since consumption utility is bounded, for sufficiently large wealth, once a critical level of consumption in each period is achieved, most of the further increases in wealth will be reinvested (because of the competition for mates) and not consumed (see CMP (Property 6]), suggesting that consumption is eventually almost constant. 
If $\gamma>1$, the consumption utility function is bounded above (by zero), and so there is a bound on how much additional utility can be offered to a potential deviator through increased consumption. This will allow us, for $\beta$ close to 1 , to use the threat of a loss of status to induce upper group women to decline offers from lower group males. A sufficient condition for such a threat to work is that there exists $\delta>0$ such that, for all $t$ and all $\beta, \hat{V}_{t}\left(\hat{k}_{t}\left(i_{l}\right)\right)-\delta \leq V^{*}\left(k_{t}^{*}\left(i_{l}\right)\right)$.

Since there is a lower bound on the gap between consumption utility in the upper and lower groups, any female in the upper group must receive a premium in the form of wealth that is sufficiently higher than $\hat{k}_{t}\left(i_{l}\right)$. This implies that any offer acceptable to an upper group female involves a sacrifice by the parents (of utility order $\delta$ ) that can only be outweighed by the upper group female having an index bounded away from $i_{l}$. Denote this bound by $\eta>0$. Thus, it is enough to deter females with index $j \in\left(i_{l}+\eta, 1\right]$, and any female in the upper group with an index $j \geq i_{l}+\eta$ suffers a status loss of at least $\eta$ per period. Once people are sufficiently wealthy, the additional utility from any increase in consumption will be dominated by the loss of status, $\beta \eta$ per period (recall that the loss of status impacts on the match of the son and so is discounted by one period). This immediately allows us to conclude that, if all the men in the upper group are sufficiently wealthy, then no woman in the upper group will be willing to deviate from the prescribed behavior. Since the initial wealth is positive, eventually all the agents in the upper group become sufficiently wealthy, and, as the proof of Proposition 4.1 below demonstrates, for sufficiently high discount factors, the gain from increased consumption before agents become sufficiently wealthy is outweighed by the loss of status.

We now turn to males in the upper group. The considerations that yield nonexistence of aristocratic equilibria when $k_{0}(0)>0$ do not arise here. Suppose there is some $t$ for which $\hat{V}_{t}\left(\hat{k}_{t}\left(i_{l}\right)\right)=V^{*}\left(k_{t}^{*}\left(i_{l}\right)\right)$. It simplifies discussion to momentarily treat male $i_{l}$ as a member of 
the upper class. Consider generation $t-1$ of family line $i_{l}$. Increasing their bequest (which incurs only a second order loss) may not allow their son to secure a marginally better mate (in contrast to the aristocratic social norm with $\left.k_{0}(0)>0\right)$. Since $\hat{k}_{t}\left(i_{l}\right)>k_{t}^{*}\left(i_{l}\right)$, relegation to the lower group necessarily results in a loss in the quality of future matches (i.e., in status). Furthermore, this loss is bounded away from zero, no matter how close to $i_{l}$ the deviating match is. Thus, by taking $\beta$ close to 1 , the discounted value of this loss can be made arbitrarily large. It is worth noting that this argument does not require the uniform wedge between consumption utilities needed to deter deviations between lower group males and upper group females.

Once we take these into account we have (the proof is in Appendix B): ${ }^{19}$

Proposition 4.1. A necessary condition for the aristocratic two-class social norm to be consistent with equilibrium is

$$
\hat{V}_{t}\left(\hat{k}_{t}\left(i_{l}\right)\right) \leq V^{*}\left(k_{t}^{*}\left(i_{l}\right)\right), \quad \forall t
$$

If $\gamma>1$ and there exist $\delta>0$ and $\bar{\beta}$ such that

$$
\hat{V}_{t}\left(\hat{k}_{t}\left(i_{l}\right)\right)-\delta \leq V^{*}\left(k_{t}^{*}\left(i_{l}\right)\right), \forall t
$$

holds for $\beta \in(\bar{\beta}, 1)$, then there exists $\overline{\bar{\beta}}>\bar{\beta}$ such that the two-class aristocratic social norm is consistent with equilibrium for $\beta \in(\overline{\bar{\beta}}, 1)$.

If two-class aristocratic status social norms are consistent with equilibrium, all family lines are at least as well off (in terms of period zero discounted utilities) in the two-class aristocratic social norm as in the wealth-is-status social norm. Those agents in the lower group receive the same

\footnotetext{
${ }^{19}$ Note that this proposition (unlike the other propositions) does not provide conditions on exogenous parameters that guarantee existence of aristocratic two-class equilibria.
} 
outcome, and so utility, as in the wealth-is-status social norm, while agents in the upper group receive the same matches, but enjoy higher consumption utility.

The argument above only demonstrates that all family lines are at least as well off under the two-class norm as under the wealth-is-status norm. Since the upper class saves less in the two-class equilibrium than in the wealth-is-status equilibrium, future generations of families in the upper class will be poorer in the two-class equilibrium than they would be in the wealth-is-status equilibrium. Hence, the argument above doesn't say anything about the welfare of these future generations. However, from Proposition 4.1, at least for family line $i_{l}$, the welfare comparison is true in every generation, not just the initial one. Thus, if the initial wealth distribution has $k_{0}(i)=\bar{k}$ for all $i \geq i_{l}$, then all generations of all family lines are at least as well off in the two-class aristocratic social norm as in the wealth-is-status social norm.

It is also worth noting that the aristocratic behavior of the individuals in the upper class in the aristocratic two-class equilibrium is supported by the existence of the lower class. There is one interpretation under which aristocratic behavior by the upper class can be sustained in an equilibrium of a model in which the only family lines are those of index $i \geq i_{l}$. Under our assumed birth process, in each period there will now be $1-i_{l}$ females born in each period. If the lowest endowment of females is $i_{l}$, then ostracism is a more severe threat than matching with the female with the lowest endowment. However, the implicit birth process underlying this lower bound is that female endowments breed true, so that siblings are being matched in each period, in which case the modelling of ostracism is problematic. A more congenial assumption is that each match gives birth to a female whose endowment is statistically independent of the mother's. In this case, the distribution of female endowments still has support $[0,1]$ (but with density $1 /\left(1-i_{l}\right)$ ), and the discussion from Section 3.2 applies. 


\subsection{A randomized two-class equilibrium}

Even if $\hat{V}_{t}\left(\hat{k}_{t}\left(i_{l}\right)\right) \leq V^{*}\left(k_{t}^{*}\left(i_{l}\right)\right)$ for all $t$ fails for $\beta$ close to 1 , it is still possible to have a two-class equilibrium. However, in order to deter deviations by agents with low aristocratic status, those at the bottom need to be given additional incentive to follow the social norm. This can be done by using a random matching rule in the upper group.

We define a randomized two-class status social norm as follows. As before, given a designated index $i_{l} \in(0,1)$, men and women are divided into two groups, a lower group $\left[0, i_{l}\right]$, and an upper group $\left(i_{l}, 1\right]$. Status for men in the lower group is determined by wealth while all males in the upper group have identical status (as long as the men in that family line have followed the prescribed matching and consumption patterns). For men and women in the upper group, matching is random; that is, any man in $\left(i_{l}, 1\right]$ is equally likely to be matched with any woman in $\left(i_{l}, 1\right]$.

Since the random matching within the upper group may match a high index woman with a man just above $i_{l}$, it is not immediate that men in the upper group will not make deviating offers to women in the upper group. Deviations from prescribed behavior for either men or women in the upper group result in their being put into the lower group, as will be all descendants in the line. In essence, a deviation from the prescribed rules in the upper group results in the family line being banished from the upper group. Since the expected value of a match for any male in the upper group is $\left(1+i_{l}\right) / 2$, being dropped into the lower group results in a loss of at least $\left(1-i_{l}\right) / 2$, since the best match possible if one is in the lower group yields $i_{l}$. Since the discounted stream of utility from consumption is maximized in the exogenous matching case, it is easy to deter men in the upper group from deviating. The maximum possible gain from deviating is improving the current match by no more than $1-i_{l}$. The discounted value of the loss of status from the next period is 
$\beta\left(1-i_{l}\right) /(2(1-\beta))$, with an additional cost coming from the need to distort consumption-savings decisions from the exogenous matching case. If $\beta \geq 2 / 3$, just the cost of loss of status is sufficient to deter males in the upper group.

There is also, however, as in the aristocratic two-class social norm, the possibility that men in the lower group may attempt to match with upper group women. As before, the lower group family lines are accumulating wealth at a faster rate than the upper group family lines. In order for the two-class social norm to be consistent with equilibrium, it is necessary that upper group women reject very wealthy suitors from the lower group. If the utility from consumption is unbounded $(\gamma<1)$, the loss of status may not be a sufficient cost to ensure that upper group women reject these suitors.

When $\gamma>1$, the consumption utility function is bounded above (by zero). Then, once people are sufficiently wealthy, the additional utility from any increase in consumption will be dominated by the loss of status, $\beta\left(1-i_{l}\right) / 2$. Here, as in Proposition 4.1 , this allows us to conclude that, first, if all the men in the upper group are sufficiently wealthy, then no woman in the upper group will deviate, and second, for sufficiently high discount factors, the gain from increased consumption before agents become sufficiently wealthy is outweighed by the loss of status.

Suppose now that the man with index $i_{l}$ and all men above him are governed by the status assignment rule described above while men below are governed by the wealth-is-status rule and that $k(i)>k\left(i_{l}\right)$ for all $i \geq i_{l}$. Given that all agents with indices greater than or equal to $i_{l}$ will not deviate from the social norm under any circumstances, those agents below can be treated as a society by themselves; nothing they do will affect the behavior of the agents in the upper group, and nothing the upper group does will impact on the lower group. But there will exist a wealth-is-status equilibrium for the agents in the lower group, considered as a distinct society. If we concatenate 
the wealth-is-status equilibrium for the lower group with the randomized social norm for the upper group, this will constitute a two-class equilibrium. This motivates our next proposition (the proof of which mimics the first part of the proof of Proposition 4.1, with $j-i_{l}+\eta$ replaced by $\left.\left(1-i_{l}\right) / 2\right)$ :

Proposition 4.2. Suppose $\gamma>1$. Fix $i_{l} \in(0,1)$ such that $k_{0}\left(i_{l}\right)>0$. There exists $\hat{\beta}<1$ such that for $\beta>\hat{\beta}$, the randomized two-class social norm with upper group $\left(i_{l}, 1\right]$ is consistent with equilibrium.

We now compare the utility levels people would have in the first period in the wealth-is-status equilibrium and the randomized two-class equilibrium. For the agents at the bottom, there is no difference since they are in a wealth-is-status equilibrium relative to the bottom group in either case. The agents at the top are not indifferent, however. Those above the average for the upper group, $\left(i_{l}+1\right) / 2$, are receiving lower expected value from their match in the randomized two-class equilibrium than in the wealth-is-status equilibrium while those below the average are receiving higher expected utility from the matches. All agents in the upper group are better off with respect to utility from consumption in the randomized two-class equilibrium since they no longer have the distortion that results from the competition in the wealth-is-status equilibrium. Thus, those males below $\left(i_{l}+1\right) / 2$ are clearly better off in the randomized two-class equilibrium since they are better off with respect to both matching and consumption.

What about the welfare of males above $\left(\dot{i}_{l}+1\right) / 2$ ? For the man with index 1 , his loss in utility from matching is $\left(1-\ddot{i}_{l}\right) / 2$. But it is possible that this loss is greater than the utility increase from consumption. In that case, this individual is strictly worse off in the randomized two-class equilibrium than in the wealth-is-status equilibrium. We do not know if two-class social norms that necessarily Pareto dominate the wealth-is-status social norm exist. 


\subsection{A three-class equilibrium}

Building on two-class equilibria, we can also construct equilibria with low, middle, and upper classes. The idea is that aristocratic matching can be supported in the upper class since the middle class has random matching. Fix $i_{l}<i^{\prime \prime}$, and define a three-class status assignment rule as follows: Status for men with index $i \leq i_{l}$ is determined by wealth-is-status, all men with index $i$ between $i_{l}$ and $i^{\prime \prime}$ have the same status (any man in $\left(i_{l}, i^{\prime \prime}\right]$ is equally likely to be matched with any woman in $\left.\left(i_{l}, i^{\prime \prime}\right]\right)$, and a man with index $i>i^{\prime \prime}$ has status $j=i$. Deviations from prescribed behavior for either men or women in either the middle or the upper class result in their being put into the class just below, as will be all descendants in the line.

In the three-class equilibria, the (one period) value of loss of status in moving from one class to the one below is at least $\left(i^{\prime \prime}-i_{l}\right) / 2$, since the expected value of a match for any male in the middle class is $\left(i^{\prime \prime}+i_{l}\right) / 2$, the infimum of status in the upper class is $i^{\prime \prime}$, and the supremum of status in the lower class is $i_{l}$. A similar argument to that showing the existence of two-class equilibria shows that three-class equilibria exist, and so we have

Proposition 4.3. Suppose $\gamma>1$. Fix $i_{l}<i^{\prime \prime} \in(0,1)$, and suppose $0<k_{0}\left(i_{l}\right) \leq k_{0}\left(i^{\prime \prime}\right)$. There exists $\hat{\beta}<1$ such that if $\beta>\hat{\beta}$, there exists a three-class equilibrium in which men with index $i>i^{\prime \prime}$ are governed by the aristocratic status assignment rule, those with index $i \in\left(i_{l}, i^{\prime \prime}\right]$ are governed by the random status assignment rule, and those with index $i \leq i_{l}$ are governed by the wealth-is-status rule. 


\section{Discussion}

We believe the equilibria we have constructed capture salient features of the class system: behavioral prescriptions differ by class, and individuals match within their class. The model makes concrete predictions about the extent to which and the manner in which social competition can be suppressed with a class system. A central feature of the analysis is that social competition is not suppressed in the lowest class. Further, the poorest family line within the class just above the poorest must enjoy a discrete advantage from being in this class if it is to be prevented from deviating. This is accomplished by the random matching rule in the randomized two-class social norm.

The particular form through which the existence of a lower class increases the possibility of cooperation that is inconsistent with self-interested behavior is reminiscent of efficiency wage models (these are surveyed in Weiss [11]). In these models, workers have the opportunity to shirk on the job, with there being a positive probability that the shirking will not be detected. The shirking, while advantageous to the worker, is inefficient in that the cost to the employer of shirking is higher than the benefit to the worker. Efficiency wage models demonstrate how unemployment, in equilibrium, can serve as a deterrent to shirking. Workers can be paid above their reservation wage, giving them a strict gain from employment as compared to unemployment. If there is no unemployment (or in other words, if workers can be sure of being immediately reemployed after losing their job), the threat of being fired imposes no cost. If, however, there is unemployment in equilibrium, a worker who is fired will not be sure of being immediately reemployed and, consequently, will be less likely to shirk. The efficiency improvements associated with decreased shirking cannot be obtained if there is full employment. The existence of an unemployed group in conjunction with a strict preference for being employed gives workers something to lose if they are caught shirking and consequently 
decreases the incentive to shirk. The parallel between the group of unemployed workers and the lowest class in our model is clear: the existence of each provides an inducement for those outside the groups to cooperate in order to stay out of these groups.

There is an important distinction, however, between our work and efficiency wage models. A central assumption in those models is anonymity. If all firms know the history of each worker, then any worker caught shirking can be punished by being paid only his or her shirking reservation wage thereafter by every firm that hires that worker. In contrast, wealth-is-status equilibria are the only anonymous equilibria in our model.

In our model, competition takes the form of over-saving. One attractive aspect of this form of competition is that it captures the intertemporal problem associated with seeking to restrain social competition: Individuals can seek to improve the position of their family line over time and thus be able to undercut social prescriptions that determine their status position. This form of competition is constructive for the individuals involved since it raises their offspring's future consumption and matching opportunities, but destructive from a social perspective since the increase in consumption is not sufficient to offset the welfare loss to the family line of forgone consumption today. While the ability to affect their future matching opportunities has a zero-sum aspect socially, the increase in wealth does enable an individual to offer his mate more consumption, hence making her better off. Purely destructive competition can arise if it serves some sort of signalling purpose. (For a discussion of conspicuous consumption as a signalling device see Cole, Mailath, and Postlewaite [3].)

While we have focused on social norm equilibria that ameliorate self-interested behavior, our analysis provides insights about the structure and existence (or nonexistence) in a broad range of models with heterogenous agents. In particular, the social norms that do not limit self-interested 
behavior do not require, implicitly or explicitly, sanctions to be imposed on deviating individuals. The equilibrium behavior is strategically similar to behavior that is sometimes called myopic or anonymous. For example, if the interaction between members of the community can be represented by repeated play of a constant stage game, then myopic behavior involves choosing a stage-game best reply to the behavior of other members. For communities with a large number of members, anonymous equilibria specify that agents react only to some aggregate statistic of behavior, disregarding the identities of agents choosing different actions; moreover, a single agent typically cannot affect the aggregate statistic. This is also related to the notion of a Markov perfect equilibrium, in which behavior only depends upon payoff-relevant aspects of history. However, multi-class social norms may allow us to construct equilibria with lower payoffs than social norms that do not involve sanctions.

\section{Appendixes}

\section{A. The Finite Horizon CMP Model}

In this appendix, we analyze the CMP model with a finite horizon: the $n^{\text {th }}$ generation is the last generation, with the output generated by the bequest from generation $n-1$ completely consumed by the son and his mate and the game ending at that point. In the last period, if a woman receives multiple offers, then she will accept the offer from the wealthiest man (since this completely determines her utility). The two period case, with a continuous and strictly increasing initial capital endowment $k_{0}$, was introduced in Section $3.1 .^{20}$ An equilibrium is described by a function $\sigma:[0,1] \rightarrow \Re_{+}$, where $\sigma(i)$ is the bequest of family $i$. Recall that women accept the wealthiest

\footnotetext{
${ }^{20} \mathrm{~A}$ two period example in which all parents have the same initial capital endowment is discussed in Section IV.A of CMP.
} 
suitor, so that matching is necessarily positively assortative, and the problem for couple $i$ in period 1 is to choose the bequest $k \in\left[0, A k_{0}(i)\right]$ to maximize

$$
u\left(A k_{0}(i)-k\right)+\beta u(A k)+\beta F(A k)
$$

If $\sigma$ is a strictly increasing bequest function followed by the other agents, ${ }^{21}$ then $F(A k)=\lambda\{i$ : $A \sigma(i) \leq A k\}=\lambda\left\{i: i \leq \sigma^{-1}(k)\right\}=\sigma^{-1}(k)$, where $\lambda$ is Lebesgue measure. The first order condition is

$$
-u^{\prime}\left(A k_{0}(i)-k\right)+\beta A u^{\prime}(A k)+\beta \frac{1}{\sigma^{\prime}\left(\sigma^{-1}(k)\right)}=0
$$

In equilibrium, $k=\sigma(i)$, so if $\sigma$ is a strictly increasing equilibrium bequest function, it satisfies the differential equation:

$$
\sigma^{\prime}(i)=\frac{\beta}{u^{\prime}\left(A k_{0}(i)-\sigma(i)\right)-\beta A u^{\prime}(A \sigma(i))}
$$

Note in particular that this requires that $\sigma(i)>k^{* *}(i)$, where $k^{* *}(i)$ solves $u^{\prime}\left(A k_{0}(i)-\sigma(i)\right)=$ $\beta A u^{\prime}(A \sigma(i))$; i.e., $k^{* *}$ is the optimal bequest in the absence of matching considerations.

Suppose that $k_{0}(0)>0$. Since the poorest family has a positive amount of wealth, it has a nontrivial optimization problem. In equilibrium, this family effectively ignores matching considerations; i.e., $\sigma(0)=k^{* *}(0)$. The reason is reminiscent of why the least productive worker chooses no education in a separating perfect Bayesian equilibrium in the Spence job market signalling model. Clearly, $\sigma(0) \geq k^{* *}(0)$. Suppose the inequality is strict. By bequeathing $\sigma(0)$, the family only ensures that the son matches with the woman with lowest endowment. If instead the family bequeaths $k^{* *}(0)$, their utility from consumption of the male good is increased, while the match is

\footnotetext{
${ }^{21}$ Standard arguments show that any equilibrium $\sigma$ must be strictly increasing and differentiable on $(0,1)$.
} 
not adversely affected-with a bequest of $\sigma(0)$ the son was the poorest male, and with a bequest of $k^{* *}(0)$ he is still the poorest male. Thus, the poorest family will bequeath $k^{* *}(0)$. This yields the initial value condition, $\sigma(0)=k^{* *}(0)$. Since $k_{0}(0)>0$, the initial value problem $((\mathrm{A} .2)$ and $\sigma(0)=k^{* *}(0)$ ) has a unique increasing solution, $\sigma(i) .{ }^{22}$ Note that $\sigma^{\prime}(i) \rightarrow+\infty$ as $i \rightarrow 0$ (otherwise the poorest family would enjoy a first order benefit in the quality of their son's match by an infinitesimal increase in their bequest, while only suffering a second order loss in the utility from consumption). In summary, when $k_{0}(0)>0$, there is a unique equilibrium, and the equilibrium bequest function solves the initial value problem described by (A.2) and $\sigma(0)=k^{* *}(0)$.

Suppose now that $k_{0}(0)=0$. Clearly, the bequest at zero must be zero; i.e., $\sigma(0)=0$. The initial value problem, however, described by (A.2) and the initial condition $\sigma(0)=0$ is badly behaved: as $i \rightarrow 0$, both $u^{\prime}\left(A k_{0}(i)-\sigma(i)\right)$ and $A u^{\prime}(A \sigma(i))$ diverge to $+\infty$.

Rather than solving for equilibrium directly in this case, we obtain the equilibrium as a limit by considering initial distributions of wealth $k_{0}+\underline{k}, \underline{k}>0$, and letting $\underline{k} \rightarrow 0$. We have just argued that if the poorest family has strictly positive wealth, then there is a unique equilibrium. Denote the equilibrium bequest function for initial distributions of wealth $k_{0}+\underline{k}$ by $\sigma(i ; \underline{k})$. Define $\sigma^{*}(i)=\inf _{\underline{k}} \sigma(i ; \underline{k})$. Since $\sigma(i ; \underline{k}) \in\left[k^{* *}(i), A k_{0}(i)+A \underline{k}\right]$ for all $i, \sigma^{*}$ is well-defined. Moreover, it satisfies (A.2) and so is differentiable. ${ }^{23}$ Since $\{\sigma(\cdot ; \underline{k})\}$ and $\sigma^{*}$ are continuous functions on the compact set $[0,1]$ and the convergence of $\sigma(\cdot ; \underline{k})$ to $\sigma^{*}$ is monotone (in fact, decreasing), the

\footnotetext{
${ }^{22}$ The inverse initial value problem, where $i(\sigma)$ is solved for as a function of the bequest $\sigma$, is Lipschitz in the relevant region. The technical issues here are similar to those that arise in the study of separating equilibria in signalling games with a continuum of types-see Mailath [8].

${ }^{23}$ Standard theorems on the continuity of solutions to differential equations cannot be applied, since neither (A.2) nor its inverse are Lipschitz. However, for fixed $i^{\prime}$ and $\epsilon$ small (so that $\left.i^{\prime}-\epsilon>0\right), \sigma^{\prime}(\dot{z} ; \underline{\underline{k}}$ ) converges uniformly to the right hand side of (A.2) for all $i \in\left[i^{\prime}-\epsilon, 1\right]$. [Note first that the family $\{\sigma(\cdot ; \underline{k})\}$ is equicontinuous, considered as functions with domain $\left[i^{\prime}-\epsilon, 1\right]$ : There exists $\eta>0$ (independent of $\underline{k}$ ) such that if $\left|\sigma-k^{* *}(i ; \underline{k})\right|\left\langle\eta\right.$, then $\left.\sigma^{\prime}(i ; \underline{k})\right\rangle$ $2 d k^{* *}(i ; \underline{k}) / d i$ for all $i \in[0,1]$, and so there exists $\delta>0$ (again, independent of $\underline{k}$ ) such that $\sigma(i ; \underline{k}) \geq k^{* *}(i ; \underline{k})+\delta$ for all $i \in\left[i^{\prime}-\epsilon, 1\right]$ and all $\underline{k}$. Then pointwise convergence of $\sigma$ to $\sigma^{*}$ is uniform on $\left[i^{\prime}-\epsilon, 1\right]$, and so $\sigma^{*}$ is uniformly continuous.] This then implies that $\sigma^{*}$ also satisfies (A.2) (see, for example, Rudin [10, Theorem 7.17]).
} 
convergence is uniform.

We will take $\sigma^{*}$ as the equilibrium bequest function in our two period example. While we expect there are additional solutions to (A.2) satisfying $\sigma(0)=0$, these cannot be obtained as the limit of the unique equilibria of the game with endowments $k_{0}(i)+\underline{k}$ as $\underline{k} \rightarrow 0$. We call $\sigma^{*}$ the robust bequest function (since it is the only bequest function close to the equilibrium bequest functions for $\underline{k}$ small). As a final note on $\sigma^{*}$, note that, since $\sigma^{*}(i) \in\left[k^{* *}(i), A i\right], d \sigma^{*} / d i$ does not diverge to $+\infty$ as $i \rightarrow 0 .^{24}$

Now consider the general finite horizon model. In the last period, women always accept the wealthiest suitor, just as in the last period of the two period model. Bequest behavior in the penultimate period maximizes (A.1), where $F$ is now the distribution of wealth in the penultimate period. For each distribution of wealth in this period, there is a unique equilibrium bequest function (if $k_{0}(0)=0$, there is a unique robust equilibrium bequest function). Since the utility of the penultimate generation is thus completely determined by the bequest received (and the distribution of wealth), women in the penultimate generation always accept the wealthiest suitor. The argument can now be applied to earlier periods.

For the case $k_{0}(0)=0$, the analysis of the previous paragraph relied on the uniqueness of the robust bequest function in the two period model. If we do not restrict attention to the robust bequest function, there are (potentially) multiple equilibria in the two period game. This raises the possibility of constructing additional equilibria of the three period model in which women do not always accept the wealthiest suitor, because the choice of suitor could affect which equilibrium is played in the two period game. This type of construction underlies the finite horizon folk theorem (see Benoit and Krishna [1] and Friedman [5]). Note that the source of intertemporal incentives

\footnotetext{
${ }^{24}$ In fact, for the case $\gamma=1$ and $k_{0}(i)=i$, using L'Hospital's rule, it easy to show that $\lim d \sigma^{*} / d i=A \beta /(1+\beta)$.
} 
that supports women not always accepting the wealthiest suitor relies on the bequest behavior of the entire community changing in response to a deviation by one player.

As we saw, if $k_{0}(0)>0$, the equilibrium is necessarily unique and the slope of the bequest function is infinite at zero. The nature of equilibria is thus qualitatively different when $k_{0}(0)=0$, in which case there may be multiple equilibria, and the bequest functions in equilibria in which women always accept the wealthiest suitor (we later refer to these as wealth-is-status equilibria) do not have infinite slope at zero.

Finally, as the horizon becomes arbitrarily long, the equilibria converge to a wealth-is-status equilibrium of the infinite horizon game. Fix the horizon length $n$. Since in every equilibrium and in every period, women accept the wealthiest suitor, the game can be viewed as a game where the set of players is the family lines, the strategy space for family line $i^{\prime}$ is the collection of sequences $\kappa \equiv\left\{\kappa_{t}\right\}_{t=0}^{n}$ satisfying $0 \leq \kappa_{t+1} \leq A \kappa_{t}$ and $\kappa_{0}=k_{0}\left(i^{\prime}\right)$, and the payoff is

$$
\mathcal{U}_{i^{\prime}}\left(\kappa,\left\{\left\{k_{t}(i)\right\}_{t=0}^{n}: i \neq i^{\prime}\right\}\right) \equiv \sum_{t=0}^{n-1} \beta^{t}\left\{u\left(A \kappa_{t}-\kappa_{t+1}\right)+m_{t}\left(\kappa_{t}\right)\right\}+\beta^{n}\left\{u\left(A \kappa_{n}\right)+m_{n}\left(\kappa_{n}\right)\right\}
$$

where $m_{t}\left(\kappa_{t}\right)=\lambda\left\{i: k_{t}(i) \leq \kappa_{t}\right\}$. The discussion above shows that this game has a unique Nash equilibrium (unique robust equilibrium if $k_{0}(0)=0$ ). Let $k_{t}^{n}:[0,1] \rightarrow \Re_{+}$be the equilibrium bequests in period $t<n$ of the $n$-period game. For fixed $t$, the sequence $\left\{k_{t}^{n}\right\}_{n=t+1}^{\infty}$ is nondecreasing and so Cauchy. Finally, since this game is continuous at infinity (see Fudenberg and Levine [6]), the limit of the equilibria will be an equilibrium of the limit game, i.e., a wealth-is-status equilibrium. 


\section{B. Proof of Proposition 4.1}

The discussion before the statement of the proposition covers the necessity part. We now prove the sufficiency part.

The proof is in two parts. We first argue that if an upper group woman suffers a loss of status of at least $\eta>0$, then for $\beta$ sufficiently large, she will not accept any offer of increased consumption. We then argue that every woman who receives an offer from an upper group man must suffer such a loss. Since the discussion before Proposition 4.1 showed that lower group family lines can only potentially profit from an offer to upper group women who will suffer a bounded (away from zero) loss, the proof is done.

B.1. - For all $\eta>0$, there exists $\beta^{\prime}$ such that for $\beta>\beta^{\prime}$, no upper group woman who loses status of at least $\eta$ will deviate.

A woman $j$ in the upper group has an equilibrium payoff of (where $k$ is the wealth of her mate)

$$
V^{*}(k)+\frac{j}{(1-\beta)}
$$

An upper bound on her payoff from accepting increased consumption in this period (via increased capital $\kappa>k$ ) and losing the upper group status of her descendants is

$$
V^{*}(\kappa)+j+\frac{\beta\left(i_{l}-\eta\right)}{(1-\beta)}
$$

This is not the best possible upper bound since in order to guarantee any status for her descendants, the family line from this period will need to make wealth-is-status consumption-savings decisions 
which yields a strictly lower discounted stream of utility than $V^{*}(\kappa)$. Women in the upper group reject increased consumption if

$$
V^{*}(k)+\frac{j}{(1-\beta)} \geq V^{*}(\kappa)+j+\frac{\beta\left(i_{l}-\eta\right)}{(1-\beta)}
$$

which (since $\gamma>1, V^{*}(\kappa)<0$ ) is implied by

$$
V^{*}(k)+\frac{\beta\left(j-i_{l}+\eta\right)}{(1-\beta)} \geq 0
$$

or

$$
\sum_{\tau=0}^{\infty} \beta^{\tau}\left\{\frac{c_{\tau}^{1-\gamma}}{(1-\gamma)}+\beta\left(j-i_{l}+\eta\right)\right\} \geq 0
$$

where $c_{\tau}=\lambda^{*} A\left[\left(1-\lambda^{*}\right) A\right]^{\tau} k$.

Fix $\epsilon>0$. There exists $\bar{c}$ such that, for all $c \geq \bar{c}$,

$$
\frac{c^{1-\gamma}}{(1-\gamma)}+\beta\left(j-i_{l}+\eta\right)>\epsilon
$$

Since $k_{0}\left(i_{l}\right)>0$, there exists $T_{1}$ such that $\left(\lambda^{\dagger} A\right)\left[\left(1-\lambda^{\dagger}\right) A\right]^{T_{1}} k_{0}\left(i_{l}\right) \geq \bar{c}$, where $\lambda^{\dagger}=1-$ $\left(A^{1-\gamma}(2 / 3)\right)^{1 / \gamma}$ (this is just $\lambda^{*}$ with $\left.\beta=2 / 3\right)$. Then, if $T \geq \max \left\{T_{1}, A^{1 / \gamma}\left(A-A^{1 / \gamma}\right)^{-1}\right\}, c_{t}\left(i_{l}\right) \equiv$ $\left(\lambda^{*} A\right)\left[\left(1-\lambda^{*}\right) A\right]^{t} k_{0}\left(i_{l}\right) \geq \bar{c}$ for all $\beta \geq 2 / 3$ and $t \geq T$. Moreover, since $k_{0}$ is nondecreasing, if $c_{t}\left(i_{l}\right) \geq \bar{c}$, then $c_{t}(i) \geq \bar{c}$ for all $i>i_{l}$.

Since wealth and consumption are increasing over time, if (B.1) is satisfied in the initial period, then it will be satisfied in every period. If we define $c_{0}^{\dagger} \equiv \lambda^{\dagger} A k_{0}\left(i_{l}\right)$, then $c_{t}(i) \geq c_{0}^{\dagger}$. The left hand 
side of (B.1) can then be rewritten as

$$
\sum_{t=0}^{T} \beta^{t}\left\{\frac{c_{t}^{1-\gamma}}{(1-\gamma)}+\beta\left(j-i_{l}+\eta\right)\right\}+\sum_{t=T+1}^{\infty} \beta^{t}\left\{\frac{c_{t}^{1-\gamma}}{(1-\gamma)}+\beta\left(j-i_{l}+\eta\right)\right\} \geq T \frac{\left(c_{0}^{\dagger}\right)^{1-\gamma}}{(1-\gamma)}+\frac{\beta^{T+1} \epsilon}{(1-\beta)}
$$

which is positive for $\beta$ sufficiently close to 1 .

\section{B.2. - Any woman accepting a deviating offer from an upper group man in period} $t \geq 1$ suffers a loss in status that is bounded away from zero (as a function of $\beta$ ).

In this step we only assume there exists $\bar{\beta}$ such that $\hat{V}_{t}\left(\hat{k}_{t}\left(i_{l}\right)\right) \leq V^{*}\left(k_{t}^{*}\left(i_{l}\right)\right)$ for all $t$ and all $\beta \in(\bar{\beta}, 1)$, then there exists $\overline{\bar{\beta}}>\bar{\beta}$ (this is slightly weaker than the condition given in the statement of Proposition 4.1). We need to show that $\hat{k}_{t}^{-1}\left(k_{t}^{*}\left(i_{l}\right)\right.$ ) does not converge to $i_{l}$ as $\beta \rightarrow 1$ (recall that $k_{t}^{*}\left(i_{l}\right)<\hat{k}_{t}\left(i_{l}\right)$, so that $\hat{k}_{t}^{-1}\left(k_{t}^{*}\left(i_{l}\right)\right)<i_{l}$ for all $\left.\beta\right)$. This is true if both the derivative of $\hat{k}_{t}$ in a neighborhood of $i_{l}$ is bounded in $\beta$ and $\hat{k}_{t}\left(i_{l}\right)-k_{t}^{*}\left(i_{l}\right)$ does not converge to zero as $\beta \rightarrow 1$.

Since $m_{t}(k)=\hat{k}_{t}^{-1}(k)$ and $k=\hat{k}_{t}(i)$ in equilibrium, (3.3) implies that

$$
\hat{k}_{t}^{\prime}(i)=\frac{\beta}{\left[u^{\prime}\left(A \hat{k}_{t-1}(i)-\hat{k}_{t}(i)\right)-\beta A u^{\prime}\left(A \hat{k}_{t}(i)-\hat{k}_{t+1}(i)\right)\right]}
$$

so that $\hat{k}_{t}$ is unbounded only if the denominator goes to zero. Since, for fixed $t$, consumption is bounded above by $A^{t} k_{0}(i)$, the denominator is close to zero only if $\hat{k}_{t}(i)-k_{t}^{\dagger}(i)$ is close to zero, where

$$
k_{t}^{\dagger}(i) \equiv\left(A+(\beta A)^{1 / \gamma}\right)^{-1}\left\{\hat{k}_{t+1}(i)+(\beta A)^{1 / \gamma} A \hat{k}_{t-1}(i)\right\}
$$

We now claim that for a neighborhood of $i_{l}$, there exists an $\epsilon>0$ such that $\hat{k}_{t}(i)-k_{t}^{\dagger}(i)>\epsilon$, which implies that the denominator of (B.2) is bounded away from zero. This follows from $\hat{k}_{t}(i)>k_{t}^{\dagger}(i)$ 
(since $\hat{k}_{t}^{\prime}>0$ ), and as $i \rightarrow i_{l}$, if $\hat{k}_{t}(i)-k_{t}^{\dagger}(i)$ converges to zero, $\hat{k}_{t}$ becomes steeper than $k_{t}^{\dagger}$ (which maintains the distance between $\hat{k}_{t}(i)$ and $k_{t}^{\dagger}(i)$ ). Moreover, $\epsilon$ can be chosen independently of $\beta$.

Now, let $k_{t+1}^{\ddagger}(i)$ be the maximizing bequest when wealth-is-status only applies to the next generation, after which matching is exogenous; i.e., $k_{t+1}^{\ddagger}(i)$ is the solution to

$$
\max _{k_{t+1}} u\left(A k_{t}(i)-k_{t+1}\right)+\beta V^{*}\left(k_{t+1}\right)+\beta m_{t+1}\left(k_{t+1}\right)
$$

Since $\hat{k}_{t+1}(i)>k_{t+1}^{\ddagger}(i)>k_{t}^{*}(i)$ and $k_{t+1}^{\ddagger}(i)-k_{t}^{*}(i)$ is bounded away from zero as $\beta \rightarrow 1$, we have that $\hat{k}_{t}\left(i_{l}\right)-k_{t}^{*}\left(i_{l}\right)$ does not converge to zero as $\beta \rightarrow 1$.

\section{References}

[1] Jean-Pierre Benoit and Vijay Krishna. Finitely repeated games. Econometrica, 53:905-922, 1985.

[2] Harold L. Cole, George J. Mailath, and Andrew Postlewaite. Social norms, savings behavior, and growth. Journal of Political Economy, 100:1092-1125, 1992.

[3] Harold L. Cole, George J. Mailath, and Andrew Postlewaite. Incorporating concern for relative wealth into economic models. Federal Reserve Bank of Minneapolis Quarterly Review, 19:12$21,1995$.

[4] Harold L. Cole, George J. Mailath, and Andrew Postlewaite. Response to 'Aristocratic equilibria'. Journal of Political Economy, 103:439-443, 1995.

[5] James W. Friedman. Cooperative equilibria in finite horizon non-cooperative supergames. Journal of Economic Theory, 35:390-398, 1985. 
[6] Drew Fudenberg and David Levine. Limit games and limit equilibria. Journal of Economic Theory, 38:261-279, 1986.

[7] Steven E. Landsburg. Aristocratic equilibria. Joumal of Political Economy, 103:434-438, 1995.

[8] George J. Mailath. Incentive compatibility in signaling games with a continuum of types. Econometrica, 55:1349-1365, 1987.

[9] Alvin Roth and Marilda A. Oliveira Sotomayer. Two-Sided Matching. Cambridge University Press, Cambridge, 1990.

[10] Walter Rudin. Principles of Mathematical Analysis. McGraw-Hill, New York, 3rd ed. edition, 1976.

[11] Andrew Weiss. Efficiency Wages: Models of Unemployment, Layoffs, and Wage Dispersion. Princeton University Press, Princeton, NJ, 1990. 